\title{
Periapical Status and Quality of Root Fillings and Coronal Restorations in an Adult Turkish Subpopulation
}

\author{
Nimet Gencoglua \\ Filiz Namdar Pekiner ${ }^{b}$ \\ Birsay Gumruc \\ Dilek Helvacioglud
}

\section{ABSTRACT}

Objectives: To investigate the quality of root fillings and coronal restorations and their association with periapical status in an adult Turkish subpopulation.

Methods: A total of 400 subjects were examined. Panoramic radiographs of all participants and additional periapical radiographs of affected teeth were processed. The frequency of root canal treatment and the periapical status of all root filled teeth were evaluated. The relationship between the radiographic quality of root fillings and coronal restorations was examined by chi-squared statistical analysis.

Results: A total of 9460 teeth were examined. The total number of root filled teeth was 890 (9.39\%), and $658(73.9 \%)$ had apical periodontitis (AP). There was a significant correlation between the presence of periapical pathology and inadequate root canal fillings $(P<.05)$. Presence of AP in root filled teeth was associated with inadequate adaptation of the filling $(\mathrm{OR}=1.097 ; P=0.54)$, and with poor radiographic quality of the coronal restoration ( $O R=0.91 ; P=0.70)$, and with poor radiographic quality of the filling restoration $(\mathrm{OR}=0.97 ; \mathrm{P}=0.92$ ). Only $24.5 \%$ of the root fillings were adequate. The highest percentage of root fillings was found in maxillary right first molars $(6.9 \%)$.

Conclusions: The results demonstrate a low prevalence of root-filled teeth and poor quality of coronal restorations and root fillings consistent with a high prevalence of apical periodontitis in a Turkish subpopulation. (Eur J Dent 2010;4:17-22)

Key words: Apical periodontitis; Coronal restoration; Endodontics; Periapical status; Root fillings.

a Professor, Marmara University, Faculty of Dentistry, Department of Endodontics, Istanbul, Turkey.

b Assistant Professor, Marmara University, Faculty of Dentistry, Department of Oral Diagnosis and Radiology, Istanbul, Turkey.

Research Associate, Marmara University, Faculty of Dentistry, Department of Oral Diagnosis and Radiology, Istanbul, Turkey.

d Research Assistant, Marmara University, Faculty of Dentistry, Department of Endodontics, Istanbul, Turkey.
- Corresponding author: Dr. Filiz Pekiner,

Marmara University, Faculty of Dentistry, Department of Oral Diagnosis and Radiology, Guzelbahce Buyukciftlik Sok. No:6 34365 Nisantasi-Istanbul, Turkey. Phone: +90 (212) 2319120 Fax: +90 (212) 2465247

E-mail: fpekinerdyahoo.com 


\section{INTRODUCTION}

According to the European Society of Endodontology (1994), the assessment of endodontic treatment requires clinical as well as radiological follow-ups at regular intervals. The radiographic evidence of success is the presence of a normal periodontal ligament space around the root. If radiographs reveal that a lesion has remained the same or has only diminished in size, the treatment is not considered a success. ${ }^{1,2}$

It is generally accepted that the outcome of endodontic treatment is positively correlated with the technical quality of the root filling, expected to provide an hermetic seal against bacterial ingress. ${ }^{3,4}$ However, it has been suggested that the quality of the coronal restoration may also have an impact on the periapical health of root-filled teeth; ${ }^{5,6}$ when the restoration quality is good, this may allow for a favorable outcome even when the root filling quality is poor. ${ }^{7}$

Attention has been focused on the prevalence and the technical quality of root fillings through the evaluation of intraoral ${ }^{8-10}$ or panoramic radiographs. 2,11,12 Epidemiologic studies have been performed on the root canal morphology in Turkish populations. ${ }^{13,14}$ Information about the prevalence and technical standard of root-canal treatment, and the occurence of periapical lesions in Turkey are scarce. ${ }^{12,15}$ Moreover, there is only one investigation about quality of root fillings and coronal restorations in Turkish population. ${ }^{16}$

The aim of the present study was to relate the quality of root canal treatment and coronal restorations to the periapical status of root filled teeth in adult Turkish population based on radiographic examination.

\section{MATERIALS AND METHODS}

Patient selection

The sample consisted of 400 subjects, aged $38.70 \pm 13.80$ years, 138 males $(34.5 \%)$ and 262 females $(65.5 \%)$, presenting consecutively as new patients seeking routine dental care in Department of Oral Diagnosis and Radiology, Faculty of Dentistry, Marmara University, Istanbul, Turkey, between 2005 and 2006. The criteria for inclusion in the study were that the patients should be attending for the first time. Patients younger than 20 years and patients having less than eight remaining teeth were excluded. All the patients gave written informed consent for the study.

\section{Radiographic examination}

All participants underwent a panoramic radiograph and additional periapical radiographs of endodontically treated teeth were processed. All panoramic and periapical radiographs were taken with a Veraviewpocs Hi-sped (J. Morita MFG. Corp., Kyoto, Japan) and Evolution X 3000-2C x-ray unit (New Life Radiology SRL, Italy), respectively. Two radiographers using the long-cone paralleling technique, setting of $70 \mathrm{kV}, 10 \mathrm{~mA}$, a film-focus distance of $30 \mathrm{~cm}$ took all periapical radiographs. Automatically developed and fixed radiographs (Dürr Dental XR-24 Pro (Dürr Dental GmbH\&Co., KG, Bissingen, Germany), Kodak Medical X-ray processor (Eastman Kodak Company, Rochester, NY, USA), General Rapid Medical Developer and Fixer (General A.S., Istanbul, Turkey)) were used in this study.

\section{Radiographic evaluation}

The viewing conditions were standardized, using a view-box with fixed light intensity. The incidence of root fillings was recorded along with the periapical status of all teeth with the exception of third molars. The length of root filling was judged as 'adequate' if the root filling was $2 \mathrm{~mm}$ or less from the radiographic apex, when it was more than $2 \mathrm{~mm}$ from the apex, it was considered as an 'underfilling' and when excess filling was beyond the radiographic apex, it was categorized as an 'overfilling'. ${ }^{17}$ The density of root filling was judged as 'adequate' if the radiodensity of fill was uniform and appeared to be radiographically adapted to the root-canal walls. It was scored as 'inadequate' if canal space was visible or if the radiodensity was not uniform. The periapical status was assessed using the 'Periapical Index' (PAI) score (Orstavik et $\left.\mathrm{al}^{18}\right)$, recorded for each one of the roots. PAI scores 1 and 2 signified a nondiseased apical periodontium, and PAI scores 3, 4, and 5 signified the presence of an apical radiolucency. The worst score of all roots was taken to represent PAI score for multirooted teeth.

In case of a root filling was present, the type of coronal restoration (crown or filling) was recorded. The quality of the restoration was assessed radiographically and classified as inadequate if the restoration was absent or if open margins, 
overhangs or secondary caries were detectable. In addition, the presence or absence of posts was noted.

Evaluation of the periapical status and the quality of root filling in the present study was made independently by two examiners (FNP, BG) using the same examination procedure after a calibration session. For calibration 20 radiographs were used and not included in main study. The Cohen's Kappa value for inter-examiner agreement of PAIvalues for all scored teeth was 0.81 . The interexaminer agreement scores gave Cohen's kappa of 0.68 for quality of filling and crown restoration, 0.83 for adaptation of fillings to canal walls, and 0.86 for length of root fillings.

\section{Statistical analysis}

The data were analyzed with SPSS (Statistical Package for Social Sciences) for windows 10.0 statistical package software. Descriptive statistical methods (mean and standard deviation) were used for the evaluation of the data. The qualitative data was compared by chi-squared test. $P$ values of less than .05 were interpreted as significant, and the level in confidence intervals was $95 \%$.

\section{RESULTS}

A total of 9460 teeth were examined, an average number of $23.63 \pm 4.35$ remaining teeth per subject. The total number of root-filled teeth was 890 (9.39\%); of which 658 (73.9\%) teeth had AP.
Table 1 shows the relationship between the length of root filling and periapical status. Apical periodontitis was found in $75.5 \%$ of teeth with adequate length of root filling, whereas if the filling was too short or long, periapical lesions were present in $72.8 \%$ and $96.2 \%$ of teeth, respectively. There was a significant correlation between the presence of periapical pathology and inadequate root canal fillings $(P<.05)$.

The relationship between the adaptation of root filling to canal walls and periapical status is shown Table 2. Root filled teeth without voids had AP in $72.9 \%$ of cases, whereas if voids were detected, AP was present in $74.7 \%$ of the teeth (P: 0.54 , odds ratio: $1.09, \mathrm{Cl}: 0.81-1.48$ ).

The relationship between the quality of the prosthetic restoration and periapical status is presented in Table 3. $75.9 \%$ of the teeth with adequate coronal restorations had AP, whereas if the coronal restoration was inadequate, AP was present in $74.2 \%$ of the teeth $(P: 0.70$, odds ratio: $0.91, \mathrm{Cl}$ : 0.58-1.45).

The relationship between the quality of the filling restoration and periapical status is presented in Table $4.72 .8 \%$ of the teeth with adequate filling restoration had $A P$, whereas if the filling restoration was inadequate, AP was present in $72.3 \%$ of the teeth (P: 0.92, odds ratio: $0.97, \mathrm{Cl}: 0.62-1.54)$.

\section{DISCUSSION}

The subjects included in this study were adult

Table 1. Length of fillings and the relation to the periapical status, percentage for healthy/ diseased.

\begin{tabular}{lccc}
\hline Length of filling & PAl & & P \\
\hline Under-filling & $194(\% 27.2)$ & Diseased $\mathrm{n}(\%)$ & \\
Adequate & $37(\% 24.5)$ & $114(\% 72.8)$ & $0.026^{*}$ \\
Over-filling & $1(\% 3.8)$ & $25(\% 96.2)$ & \\
Total & $232(\% 26.1)$ & $658(\% 73.9)$ & \\
\hline
\end{tabular}

Chi-square test *: $\mathrm{P}<.05$

Table 2. Adaptation of fillings to the canal walls and the relation to the periapical status, percentage for healthy/ diseased.

\begin{tabular}{lccc}
\hline Adaptation of filling & PAI & & P \\
\hline Adequate & Healthy $\mathrm{n}(\%)$ & Diseased $\mathrm{n}(\%)$ & \\
Inadequate & $104(\% 27.1)$ & $280(\% 72.9)$ & 0.548 \\
Total & $128(\% 25.3)$ & $378(\% 74.7)$ & \\
\hline
\end{tabular}

Chi-square test (P:0.548; Odds ratio:1.097; $\mathrm{Cl}: 0.81-1.48)$ 
patients attending for general dental treatment for the first time. The recruitment of subjects was the same as those used by others. 8,11,17,19,20 There is no information available for this patient population, which makes it difficult to extrapolate the data obtained into the Turkish population. However, the dental faculty attracts a patient population from numerous parts of the city and its surroundings, which eliminates the risk of only including patients previously treated by a limited number of practitioners. Some patients sought care because of the expense of prosthetic treatment, which in general is less at the dental faculty than in the private sector in Turkey. In addition, extraction of teeth due to low socio-economic status gives rise to a limited number of root filled teeth epidemiologically.

Patients with eight or fewer remaining teeth were excluded because they often had periodontal disease and it was impossible to determine the role played by the endodontic treatment in the occurrence of a radiographic periapical lesion. ${ }^{17}$

Although studies comparing panoramic and periapical radiographs for detecting periapical lesions indicate similar overall diagnostic accura$c y,{ }^{21,22}$ panoramic radiographs are claimed to show lower sensitivity when detecting periapical lesions of the anterior teeth and mandibular molars compared with periapical radiographs. ${ }^{23}$ Therefore, there is a possibility for loss of information when endodontic conditions are recorded based on pan- oramic radiographs only in some studies. 2,11,17,24-26 However, other epidemiological studies have used a combination of panoramic and periapical radiographs. 4,8,9,27 As panoramic radiographs do not reveal details and inter-observer variability is greater with panoramic radiographs. ${ }^{28}$ In this investigation, therefore, all participants underwent a panoramic and additional periapical radiographs of affected teeth were processed.

Criteria for AP vary among studies. ${ }^{2,10,29,30}$ In recent years, most of the studies on the prevalence of AP have used this index scoring to assess periapical status, so the results of this study can be more appropriately compared with them..$^{4,18,25}$ Therefore, in the present study, the PAI was used to assess the periapical status. The reproducibility of the observer (Cohen's kappa=0.81) was acceptable, probably because of prior calibration.

A total of 890 teeth had root fillings, accounting for $9.39 \%$ of all teeth. The prevalence of root-filled teeth in the Turkish population was found lower than previously done other studies about different countries (34\%-87\%). 4,5,9,10,19,27,29 This phenomenon can be explained by the fact that first, the survey population was not representative of the whole country, and secondly, the differences in health care services and socioeconomical factors in the various countries could account for these discrepancies. In contrast, other studies found the prevalence of root-filled teeth to range between $1.3 \%$ and $4.8 \%$, similar to that found in this study. $8,17,30-32$

The quality of endodontic treatment was disap-

Table 3. Quality of crown restoration on root filled teeth and the relation to the periapical status, percentage for healthy/diseased.

\begin{tabular}{lccc}
\hline Crown restoration & PAl & & P \\
\hline Adequate & Healthy $\mathbf{n}(\%)$ & Diseased $\mathbf{n}(\%)$ & \\
Inadequate & $48(\% 24.1)$ & $151(\% 75.9)$ & 0.704 \\
Total & $49(\% 25.8)$ & $141(\% 74.2)$ & \\
\hline
\end{tabular}

Chi-square test (P:0.704; Odds ratio:0.915; Cl:0.58-1.45)

Table 4. Quality of filling restoration on root filled teeth and the relation to the periapical status, percentage for healthy/diseased.

\begin{tabular}{lccc}
\hline Filling restoration & & PAl & \\
\hline Adequate & Healthy $\mathrm{n}(\%)$ & Diseased $\mathrm{n}(\%)$ & \\
Inadequate & $43(\% 27.2)$ & $115(\% 72.8)$ & 0.923 \\
Total & $65(\% 27.7)$ & $170(\% 72.3)$ & \\
\hline
\end{tabular}

Chi-square test (P:0.923; Odds ratio:0.978; $\mathrm{Cl}: 0.62-1.54)$ 
pointing. Root filling length was found to be adequate in $24.5 \%$ of the teeth and the adaptation of fillings to the canal walls in $27.1 \%$ of the teeth. In this respect, the data confirm the findings of several other investigators showing poor quality of root canal treatment. ${ }^{8,17,19}$ Apical periodontitis was found in $75.5 \%$ of teeth with adequate length of root filling, whereas if the filling was too short or long, periapical lesions were present in $72.8 \%$ and $96.2 \%$ of teeth, respectively. The findings of previously published studies support these results. Tsuneishi et $\mathrm{al}^{29}$ observed apical radiolucency most often in overfilled teeth (79.8\%), followed by adequately filled teeth $(41.6 \%)$ and then underfilled teeth (34.5\%). Siquera et $\mathrm{al}^{33}$ indicated that poor outcome in case of overfillings is usually associated with concurrent endodontic infection, or as a result of previous overinstrumentation of an infected root canal that propelled infected dentin chips to the periradicular tissues or can be due to a lack of apical seal that allows the traffic of tissue fluids into the canal and of microorganisms and their products towards the periradicular tissues. In contrast, Sunay et $\mathrm{al}^{12}$ reported $90.8 \%$ of root-filled teeth with apical periodontitis had inadequate root canal fillings, the majority of them being short of the radiographic apex. Dugas et $\mathrm{al}^{4}$ reported the prevalence of apical periodontitis close to $60 \%$ when the root filling was inadequate, regardless of whether the filling was too short or too long consistent with the observations in other studies. $17,19,27$

In the present study, the relationship between the type of coronal restoration within root filled teeth and the presence of apical periodontitis were investigated. It is indicated that the technical quality of the coronal restoration may be more important for periapical health than the technical quality of the root filling. ${ }^{34}$ Although some researchers found a significant correlation between the radiographic quality of the coronal restoration and the periapical status of root filled teeth. ${ }^{4,5}$ On the other hand, Hommez et al ${ }^{35}$ reported that the quality of the coronal restoration did not have a significant influence on the periradicular status when it was combined with the quality of endodontic treatment. The results of the present study revealed that the quality of the restoration did not significantly affect the treatment outcome.

\section{CONCLUSIONS}

In the present study, the frequency of endodontically treated teeth was found lower than other studies. The technical quality of root fillings and restoration in a Turkish subpopulation was poor and was consistent with a high prevalence of apical periodontitis.

\section{REFERENCES}

1. Consensus report of the European Society of Endodontology on quality guidelines for endodontic treatment. Int Endod $J$ 1994;27:115-124.

2. Lupi-Pegurier L, Bertrand MF, Muller-Bolla M, Rocca JP, Bolla M. Periapical status, prevalence and quality of endodontic treatment in an adult French population. Int Endod $J$ 2002;35:690-697.

3. Sjogren U, Hagglund B, Sundqvist G, Wing K. Factors affecting the long-term results of endodontic treatment. $J$ Endod 1990;16:498-504.

4. Dugas NN, Lawrence HP, Teplitsky PE, Pharoah MJ, Friedman S. Periapical health and treatment quality assessment of root-filled teeth in two Canadian populations. Int Endod J 2003;36:181-192.

5. Kirkevang LL, Ørstavik D, Hörsted-Bindslev P, Wenzel A. Periapical status and quality of root fillings and coronal restorations in a Danish population. Int Endod $J$ 2000;33:509-515.

6. Tronstad L, Asbjørnsen K, Doving L, Pedersen I, Eriksen HM. Influence of coronal restorations on the periapical health of endodontically treated teeth. Endod Dent Traumatol 2000;16:218-221.

7. Ray HA, Trope M. Periapical status of endodontically treated teeth in relation to the technical quality of the root filling and coronal restoration. Int Endod J 1995;28:12-18.

8. Weiger R, Hitzler S, Hermle G, Löst C. Periapical status, quality of root canal fillings and estimated endodontic treatment needs in an urban German population. Endod Dent Traumatol 1997;13:69-74.

9. Sidaravicius B, Aleksejuniene J, Eriksen HM. Endodontic treatment and prevalence of apical periodontitis in an adult population of Vilnius, Lithuania. Endod Dent Traumatol $1999 ; 15: 210-215$.

10. Segura-Egea JJ, Jiménez-Pinzón $A$, Poyato-Ferrera $M$, Velasco-Ortega E, Ríos-Santos JV. Periapical status and quality of root fillings and coronal restorations in an adult Spanish population. Int Endod J 2004;37:525-530.

11. De Moor RJ, Hommez GM, De Boever JG, Delmé KI, Martens GE. Periapical health related to the quality of root canal treatment in a Belgian population. Int Endod $J$ 2000;33:113-120. 
12. Sunay H, Tanalp J, Dikbas I, Bayirli G. Cross-sectional evaluation of the periapical status and quality of root canal treatment in selected population of urban Turkish adults. Int Endod $J$ 2007;40:139-145.

13. Haznedaroḡlu F, Ersev H, Odabași H, Yetkin G, Batur B, Așçi S, Issever H. Incidence of patent furcal accessory canals in permanent molars of a Turkish population. Int Endod $J$ 2003;36:515-519.

14. Sert S, Bayirli GS. Evaluation of the root canal configurations of the mandibular and maxillary permanent teeth by gender in the Turkish population. J Endod 2004;30:391-398.

15. Er O, Sagsen B, Maden M, Cinar S, Kahraman Y. Radiographic technical quality of root fillings performed by dental students in Turkey. Int Endod J 2006;39:867-872.

16. Kayahan MB, Malkondu O, Canpolat C, Kaptan F, Bayirli G, Kazazoglu E. Periapical health related to the type of coronal restorations and quality of root canal fillings in a Turkish subpopulation. Oral Surg Oral Med Oral Pathol Oral Radiol Endod 2008;105:e58-62.

17. De Cleen MJ, Schuurs AH, Wesselink PR, Wu MK. Periapical status and prevalence of endodontic treatment in adult Ducth population. Int Endod $J$ 1993;26:112-119.

18. Orstavik D, Kerekes K, Eriksen HM. The periapical index: a scoring system for radiographic assessment of apical periodontitis. Endod Dent Traumatol 1986;2:20-34.

19. Saunders WP, Saunders EM, Sadiq J, Cruickshank E. Technical standard of root canal treatment in an adult Scottish sub-population. Br Dent J 1997;182:382-386.

20. Boucher Y, Matossian L, Rilliard F, Machtou P. Radiographic evaluation of the prevalence and technical quality of root canal treatment in a French subpopulation. Int Endod J 2002;35:229-238.

21. Rohlin M, Kullendorff B, Ahlqwist M, Henrikson CO, Hollender L, Stenström B. Comparison between panoramic and periapical radiography in the diagnosis of periapical bone lesions. Dentomaxillofac Radiol 1989;18:151-155.

22. Molander B, Ahlqwist M, Gröndahl HG, Hollender L. Comparison of panoramic and intraoral radiography for the diagnosis of caries and periapical pathology. Dentomaxillofac Radiol 1993;22:28-32.

23. Molander B, Ahlqwist M, Gröndahl HG. Panoramic and restrictive intraoral radiography in comprehensive oral radiographic diagnosis. Eur J Oral Sci 1995;103:191-198.

24. Ahlqwist M, Halling A, Hollender L. Rotational panoramic radiography in epidemiological studies of dental health. Comparison between panoramic radiographs and intraoral full mouth surveys. Swed Dent J 1986;10:73-84.

25. Skudutyte-Rysstad R, Eriksen HM. Endodontic status amongst 35-year-old Oslo citizens and changes over a 30year period. Int Endod J 2006;39:637-642.
26. Loftus JJ, Keating AP, McCartan BE. Periapical status and quality of endodontic treatment in an adult Irish population. Int Endod $J$ 2005;38:81-86.

27. Eriksen HM, Bjertness E. Prevalence of apical periodontitis and results of endodontic treatment in middle-aged adults in Norway. Endod Dent Traumatol 1991;7:1-4.

28. Flint DJ, Paunovich E, Moore WS, Wofford DT, Hermesch CB. A diagnostic comparison of panoramic and intraoral radiographs. Oral Surg Oral Med Oral Pathol Oral Radiol Endod 1998;85:731-735

29. Tsuneishi M, Yamamoto T, Yamanaka R, Tamaki N, Sakamoto T, Tsuji K, Watanabe T. Radiographic evaluation of periapical status and prevalence of endodontic treatment in an adult Japanese population. Oral Surg Oral Med Oral Pathol Oral Radiol Endod 2005;100:631-635.

30. Jiménez-Pinzón $A$, Segura-Egea JJ, Poyato-Ferrera $M$, Velasco-Ortega E, Ríos-Santos JV. Prevalence of apical periodontitis and frequency of root-filled teeth in an adult Spanish population. Int Endod J 2004;37:167-173.

31. Eriksen HM, Berset GP, Hansen BF, Bjertness E. Changes in endodontic status 1973-93 among 35-year-olds in Oslo, Norway. Int Endod J 1995;28:129-132.

32. Kirkevang LL, Hörsted-Bindslev P, Ørstavik D, Wenzel A. Frequency and distribution of endodontically treated teeth and apical periodontitis in an urban Danish population. Int Endod J 2001;34:198-205.

33. Siqueira JF Jr, Rôças IN, Alves FR, Campos LC. Periradicular status related to the quality of coronal restorations and root canal fillings in a Brazilian population. Oral Surg Oral Med Oral Pathol Oral Radiol Endod 2005;100:369-374.

34. Ray HA, Trope M. Periapical status of endodontically treated teeth in relation to the technical quality of root filling and the coronal restoration. Int Endod J 1995;28:12-18.

35. Hommez GM, Coppens CR, De Moor RJ. Periapical health related to the quality of coronal restorations and root fillings. Int Endod $J$ 2002;35:680-689. 